\title{
Ultrastructure of Intradentinal Nerves After Resection of the Inferior Alveolar Nerve in Mice
}

\author{
R. E. CORPRON, J. K. AVERY, and C. F. COX
}

Departments of Pedodontics and Oral Biology, School of Dentistry, The University of Michigan, Ann Arbor, Michigan 48104, USA

Intradentinal nerves in humans have been described by light microscopic techniques by Fearnhead ( $J$ Anat 91:267-277, 1957), Rapp, Avery, and Rector ( $J$ Canad Dent Assn 23: 447-453, 1957), Arwill (Trans $R$ Sch Dent 3:1-88, 1958), and Bernick ( $J$ Dent Res 43:406-411, 1969). Ultrastructure of intradentinal nerves has been reported by Frank (Dentine and Pulp, N. B. B. SYMONS (ed), 1968, pp 115-145).

Although the presence of nerves in predentin and in calcified dentin has been established, the origin of these nerves has remained in doubt. Fearnhead (Proc Roy Soc Med 54:877$884,1961)$ found no intradentinal nerves in a monkey after resection of the inferior alveolar nerve. However, there is no ultrastructural evidence to date to clarify whether the nerves present in predentin or circumpulpal dentin are from the inferior alveolar or sympathetic nerves.

The present observations are from first molars of mature white mice ( 50 days) in which the inferior alveolar nerve was resected by the inframandibular approach on the right side; the teeth of the left side served as controls. Verification of resection was established by gross dissection at the time of killing. At 21 days after resection, the teeth were fixed in $1.33 \%$ osmic acid in $s$-collidine buffer at $4 \mathrm{C}$ for two hours, dehydrated through graded alcohols and propylene oxide, embedded in Epon 812 , sectioned at 500 to $800 \mathrm{~A}$, and viewed with an electron microscope.*

Nerve fibers from both the control and resected teeth were selected for comparison from similar locations, namely at the odontoblastic-predentinal border at a cuspal tip. Small unmyelinated nerve fibers from the normal side located just inside the predentin from the odontoblast exhibited a central axon that contained a mitochondrion, several large vesicles, and cross-sectioned neurofilaments. The axon was surrounded completely by a Schwann cell (Fig 1). The nerve fiber from the resected side also was a small unmyelinated nerve located at the odontoblastic-predentinal border. The nerve exhibited an axon that appeared badly shrunken and degenerated and that contained a large dark body and apparent remnants of a mitochondrion, but no vesicles (Fig 2 ). The Schwann cell surrounding the degen-

This work was supported by USPHS Research Grant DE-01604 from the National Institute of Dental Research, National Institutes of Health, Bethesda, Md.

Additional information available on request to authors.

Received for publication August 2, 1971.

* Hitachi 8, Hitachi Ltd., Tokyo, Jap. erating axon contained two lysosomal-like bodies, several small vesicles, and solitary ribosomes. Therefore, the origin of this degenerating nerve fiber is clearly from the resected inferior alveolar nerve. Further studies of the effect of resection of the cervical sympathetic nerves are in progress.
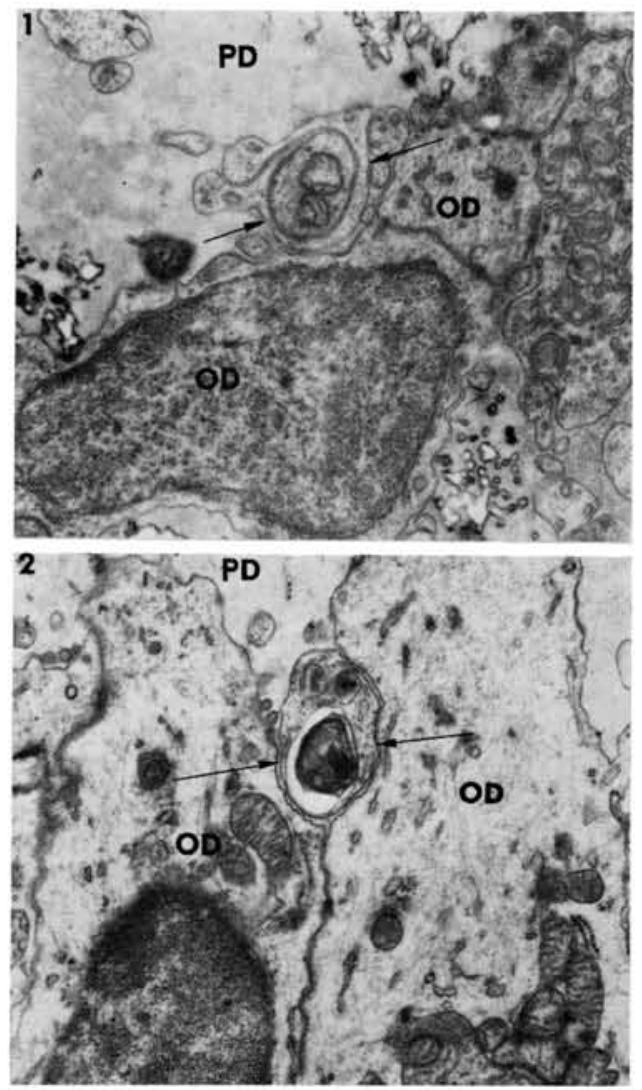

FIG 1.-Small unmyelinated nerve (arrows) from control tooth appears at predentinal $(P D)$, odontoblastic $(O D)$ border.

FIG 2.-Small degenerating, unmyelinated nerve (arrows) from molar on resected side appears between two adjacent adontoblasts $(O D)$ at the predentinal $(P D)$, odontoblastic border. 